
Rodrigues; Suzana Queiroga da Costa

\title{
Aprendizagem organizacional em unidades de informação: do grupo focal à comunidade de prática
}

Emeide Nóbrega Duarte

Doutora em Administração/UFPB.

Alzira Karla Araújo da Silva

Doutoranda em Ciência da Informação/UFMG.

Edilene Toscano Galdino dos Santos

Mestre em Biblioteconomia/UFPB.

Izabel França de Lima

Doutoranda em Ciência da Informação/UFMG.

Marcos Paulo Farias Rodrigues

Graduado em Biblioteconomia/UFPB.

Suzana Queiroga da Costa

Graduada em Biblioteconomis/UFPB.

Apresenta os resultados do mapeamento das práticas para a promoção da aprendizagem organizacional. Registra a possibilidade de originar o processo de aprendizagem com as próprias experiências e as dos outros, ao adotar-se a técnica de grupo focal, facilitadora da formação de "comunidades de prática". Caracteriza-se como estudo de caso múltiplo em unidades de informação, instrumentalizado pela entrevista e observação, tendo como sujeitos os bibliotecários. Conclui que a partilha de experiências possibilita a construção de um conhecimento coletivo de aprendizagem e identidade.

Palavras-chave: Aprendizagem organizacional; Grupo focal; Unidade de informação; Comunidade de prática. 


\title{
Organizational learning in the information units: from focus group to community of practice
}

\begin{abstract}
This work shows the results of mapping of some practices applied for the promotion of organizational learning. It registers the possibility of originating the process of learning from one's own experiences as well as from others' when the focus group technique is adopted to facilitate the formation of "communities of practice". It is characterized as a multiple case study in information units, based on interviews and observation of librarians. It was concluded that shared experiences can build collective learning knowledge and identity.
\end{abstract}

Keywords: Organizational learning; Focal group; Information units; Community of practice.

Recebido em 21.02.2008 Aceito em 13.10.2008

\section{Introdução}

Com a implementação de um projeto de pesquisa, mapeamos as práticas desenvolvidas em bibliotecas universitárias (Biblioteca Central da Universidade Federal da Paraíba (UFPB) (setor público) e Biblioteca Central do Centro Universitário de Ensino da Paraíba (UNIPÊ), setor privado), identificando, nas falas das pessoas-chave dessas Bibliotecas, elementos das dimensões contidas num modelo alternativo de organização do conhecimento, apresentado por Angeloni (2002). Assim, percebemos a relevância da aprendizagem organizacional ao adotarmos a técnica de grupo focal.

No modelo de organização do conhecimento usado como parâmetro, a primeira dimensão está relacionada à infra-estrutura organizacional, referindo-se à construção de um ambiente favorável ao objetivo da organização do conhecimento. A segunda dimensão refere-se às pessoas que, nas organizações do conhecimento, são profissionais qualificados, e cujas características são necessárias às atividades do conhecimento. A terceira dimensão diz respeito à tecnologia, funcionando como suporte para a criação, disseminação e armazenamento do conhecimento. $\mathrm{Na}$ dimensão pessoas, a aprendizagem aparece como uma variável considerada necessária para que as organizações possam fazer frente às mudanças macro e microambientais (ANGELONI, 2002). 
Fundamentados no modelo citado, planejamos a coleta dos dados adotando a técnica de grupo focal, instrumentalizada por entrevista e observação. Esses instrumentos foram aplicados durante um encontro de "Integração de Equipes", intitulado "Chá de compartilhamento de conhecimento", que reuniu a equipe de bibliotecários da UFPB, a do UNIPE e a equipe responsável pela pesquisa, obtendo-se aspectos relativos à aprendizagem organizacional em grupo focal.

Neste artigo, apresentamos o mapeamento das práticas, nas bibliotecas universitárias estudadas, para a promoção da aprendizagem organizacional, registrando a possibilidade de favorecimento do processo de aprendizagem com as próprias experiências e as dos outros, ao se adotar a técnica de grupo focal.

A abordagem fundamenta-se nos pressupostos da organização que aprende, entendida como aquela que "[...] dispõe de habilidades para criar, adquirir e transferir conhecimento e é capaz de modificar seu comportamento, de modo a refletir os novos conhecimentos e idéias" (GARVIN, 2000, p. 54).

\section{Aprendizagem organizacional e conhecimento}

A aprendizagem pode ser entendida como um "processo de mudança provocado por estímulos diversos e mediado por emoções que podem ou não produzir mudança no comportamento da pessoa" (FLEURY; OLIVEIRA JÚNIOR, 1999, p.134). Aprende-se lendo, ouvindo, errando, na prática, vivenciando situações na própria cabeça e observando os outros. Inúmeras são as formas de aprender, e cada pessoa se vê única nesse processo.

Os psicólogos enfatizam a necessidade de distinguir o processo de aprendizagem, que ocorre dentro do organismo da pessoa que aprende, das respostas emitidas por essa pessoa, as quais podem ser observáveis e mensuráveis. Duas vertentes teóricas sustentam os principais modelos de aprendizagem: o modelo behaviorista e o modelo cognitivista. O modelo behaviorista tem como foco principal o comportamento, pois este é observável e mensurável, e parte do princípio de que a análise do comportamento significa 0 estudo das relações entre eventos estimuladores e respostas. Planejar o processo de aprendizagem implica estruturar esse processo passível de observação, mensuração e réplica científica. O modelo cognitivista pretende ser mais abrangente do que o behaviorista, explicando os fenômenos mais complexos como a aprendizagem de conceitos e a solução de problemas. Procura utilizar tanto dados objetivos, comportamentais, como dados subjetivos, considerando crenças e percepções do indivíduo, as quais influenciam seu processo de apreensão da realidade (FLEURY; OLIVEIRA JÚNIOR, 1999). 
Segundo Fleury e Oliveira Júnior (1999; 2002), as discussões sobre aprendizagem em organizações enraízam-se mais fortemente na perspectiva cognitivista, como no caso aqui estudado, enfatizando, especialmente, as mudanças comportamentais observáveis. Podem, então, procurar responder como as pessoas aprendem e desenvolvem as competências necessárias à organização e ao próprio projeto de vida.

Numa organização, o processo de aprendizagem pode ocorrer em três níveis. No nível do indivíduo, refere-se ao processo de aprendizagem que "está carregado de emoções positivas ou negativas, por meios de caminhos diversos". No nível do grupo, aqui aplicado, "a aprendizagem pode vir a constituir um processo social partilhado pelas pessoas do grupo". No nível da organização,...

[...] o processo de aprendizagem individual, de compreensão e interpretação partilhadas pelo grupo torna-se institucionalizado e se expressa em diversos artefatos organizacionais, como estrutura, regras, procedimentos e elementos simbólicos. As organizações desenvolvem memórias que retêm e recuperam informações (FLEURY; OLIVEIRA JÚNIOR, 1999, p.134-135).

Segundo Tacla e Figueiredo (2002), os processos de aprendizagem para aquisição de conhecimento podem ocorrer de forma externa e interna. O autor apresenta como processos de aquisição de aprendizagem para obtenção externa de conhecimento a contratação de especialistas, de consultores externos, o treinamento externo, a participação em congressos e seminários e a interação com clientes e fornecedores. Como processo de aprendizagem por meio da obtenção interna de conhecimentos, pode-se desenvolver atividades de pesquisa e desenvolvimento, treinamentos internos de funcionários, atividades de rotina, mecanismos do tipo "aprender-fazendo" e aprendizagem por pesquisa.

Faz-se necessário considerar que o processo de aprendizagem está intimamente ligado à gestão do conhecimento. O conhecimento é um recurso que pode e deve ser gerenciado para melhorar o desempenho das organizações. Para que isso aconteça, é preciso que elas descubram as formas pelas quais o processo de aprendizagem pode ser estimulado e que investiguem como 0 conhecimento organizacional pode ser administrado para atender às suas necessidades estratégicas, disseminado e aplicado por todos como uma ferramenta para o sucesso organizacional.

Para aquisição e desenvolvimento de conhecimentos, Fleury e Fleury (2001) apontam três modalidades: resolução sistemática de problemas, contratação de pessoal e experiências realizadas por outros. Para a disseminação do conhecimento, os autores apresentam os processos de 
comunicação e circulação de conhecimentos, o treinamento, a rotação de pessoas e o trabalho em equipes diversas. A observação das experiências realizadas por outras organizações pode constituir um importante caminho para a aprendizagem organizacional. A interação com pessoas de background cultural diferente - em termos de origem, formação ou experiência profissional - propicia a disseminação de idéias e o surgimento de propostas e soluções para os problemas.

Garvin (2000), por sua vez, identifica cinco vias possíveis para a aprendizagem, quais sejam: a) resolução sistemática de problemas; b) experimentação; c) experiência passada; d) circulação de conhecimento; e) experiências realizadas por outras organizações. Senge (1990), focando a aprendizagem individual dentro da organização, ressalta cinco disciplinas fundamentais à constituição de organizações que aprendem, são elas: a) raciocínio sistêmico; b) domínio pessoal; c) modelos mentais; d) objetivo comum; e) aprendizado em grupo.

O conhecimento, na economia da aprendizagem, "inclui as habilidades práticas estabelecidas com a aprendizagem, como as potencialidades adquiridas com a instrução formal e treinamento, inserindo habilidades de gerência aprendidas na prática assim como as novas produzidas por P\&D" (MEIRELLES, 2002, p. 277).

Processos bastante interessantes de construção e disponibilização do conhecimento são explorados por alguns pesquisadores que estudam as chamadas comunidades de prática. Esse conceito foi lançado como comunidades que reúnem pessoas unidas informalmente por interesses comuns no aprendizado e principalmente na sua aplicação prática (MENGALLI, 2008).

Comunidades de prática são, portanto, grupos formados em torno da prática de sua profissão, ligados pela necessidade de partilhar experiências e desenvolver um conhecimento coletivo. As pessoas necessitam trocar experiências com seus colegas e envidar esforços para se reunir e partilhar histórias para construir um conhecimento que os ajude a enfrentar os problemas que surgem. Ser membro de uma comunidade de prática implica, portanto, partilhar com os companheiros um processo contínuo de aprendizagem, de geração de conhecimento e de identidade (FLEURY; FLEURY, 2001). Assim, pode ser uma "comunidade que aprende", com o objetivo de agregar as melhores práticas.

Duguid e Brown (2001) argumentam que a prática compartilhada ao longo do tempo habilita os participantes a desenvolver uma perspectiva comum, entender seu trabalho e como este se ajusta ao ambiente circundante, unindo-os em uma comunidade informal. Eles desenvolveram a noção de comunidade de prática para se referirem à aprendizagem como um processo pelo qual os indivíduos formam suas identidades em relação às identidades sociais do grupo. No outro argumento, encontra-se uma caracterização da aprendizagem como um processo de engajamento na prática $e$, assim, de alguém se tornar membro de um grupo social de praticantes. 
Os casos aqui estudados não implicaram, objetivamente, a construção de uma comunidade de prática. No entanto, a idéia de discutir assuntos atuais pertinentes às práticas adotadas em duas Bibliotecas Universitárias, por meio de um evento denominado "Chá de Compartilhamento de Conhecimentos", indicou a necessidade de se criar essa comunidade, que, ao ser estimulada, surgiu espontaneamente, pelo uso da técnica de grupo focal em ambiente de coleta de dados.

\section{Considerações sobre o grupo focal}

Grupo focal (GF) é um grupo de discussão informal e de tamanho reduzido, com o propósito de se obter informações de caráter qualitativo em profundidade. É uma técnica rápida e de baixo custo para avaliação e obtenção de dados e informações qualitativas, fornecendo aos gerentes de projetos ou instituições uma grande riqueza de informações qualitativas sobre o desempenho de atividades desenvolvidas, prestação de serviços, novos produtos ou outras questões (GOMES; BARBOSA, 1999).

O emprego dessa técnica tem crescido, sendo considerada econômica e direcionada. Pode ser caracterizada como um recurso para compreender o processo de construção das percepções, atitudes e representações sociais de grupos humanos (VEIGA; GONDIM, 2001).

As principais características de um grupo focal são: cada grupo é organizado com um pequeno número de pessoas (entre 7 e 12), a fim de incentivar a interação entre os membros; cada sessão dura de uma a duas horas; a conversação concentra-se em poucos tópicos e o moderador tem uma agenda onde estão delineados os principais tópicos a serem abordados, os quais são, geralmente, pouco abrangentes, de modo que a conversação sobre os mesmos se torne relevante; pode haver a presença de observador externo para captar reações dos participantes; utilizam-se questões e respostas não estruturadas, que podem contribuir com novas idéias sobre o assunto investigado; os participantes não devem sentir que fazem parte de um estudo, mas, sim, que são informantes; eles devem captar informações e dar informações.

As vantagens de trabalhar com o grupo focal são: o clima relaxado das discussões; a confiança dos participantes em expressar suas opiniões; a sua participação ativa; a obtenção de informações que não ficam limitadas a uma prévia concepção dos avaliadores; bem como a alta qualidade das informações obtidas. Por outro lado, apresenta desvantagens, tais como: dificuldades para conseguir participantes, quando estes devem obedecer a critérios muito específicos; a produção de polêmicas e oposições na discussão; além de invalidação dos achados devido à ingerência de alguns dos participantes (VEIGA; GONDIM, 2001).

Para desenvolver o GF, a equipe deve constituir-se de moderador e observadores. O moderador é quem conduz o grupo focal, administrando todos os passos do grupo, mantendo o ritmo da reunião de maneira que todos os participantes da pesquisa não se percam nas anotações, promovendo a participação de todos para evitar a dispersão do grupo e o 
monopólio de um participante. Ele fará as apresentações das questões que serão respondidas e debatidas pelos participantes. O papel dos observadores é de extrema importância, pois observam os grupos anotando os seus gestos, comentários, falatórios ou algo que não está sendo escrito por eles mesmos, registrando todos os acontecimentos no decorrer do grupo (VEIGA; GONDIM, 2001).

A coleta dos dados, por sua vez, é feita de duas maneiras: através de respostas dos participantes, que são registradas individualmente por cada um, e do registro dos gestos, comentários ou falatórios de cada participante nos debates regidos pelo moderador. A seção pode ser gravada ou simplesmente anotada pelos observadores (VEIGA; GONDIM, 2001).

Para a aplicação da técnica do GF, o local em que os encontros são desenvolvidos deve favorecer a interação entre os participantes: uma sala com cadeiras confortáveis ou um círculo em volta de uma mesa é suficiente. A literatura recomenda que os encontros durem entre $1 \frac{1}{2}$ a 2 horas, no máximo 3 horas, com utilização de equipamento que registre as discussões, preferencialmente dois gravadores, e a identificação de cada participante com um cartão (VEIGA; GONDIM, 2001).

O facilitador inicia o encontro com uma breve explanação, agradecendo as presenças, e propõe uma breve auto-apresentação. Explica os objetivos do encontro, como foram selecionados os participantes e porque não foram dadas muitas informações sobre a reunião até aquele momento; e também sobre o uso de gravadores e sobre o sigilo das informações obtidas. Deixa claro que todas as opiniões interessam e, portanto, não existem boas ou más opiniões. Assim, cada membro fala na sua vez, permitindo uma boa gravação. É necessário informar aos participantes a duração do encontro e como este é desenvolvido, procedendo, também, a uma roda inicial de falas, possibilitando a todos um comentário geral sobre o tema.

Nesse contexto, os grupos focais são pequenos grupos de pessoas reunidas para avaliar conceitos ou identificar problemas, possibilitando, através de um fórum de discussão, a construção de um conhecimento coletivo do grupo (RESSEL; GUALDA; GONZÁLES, 2002 citado por DIAS, 2000).

\section{Características da pesquisa}

A escolha do ambiente onde se realizou a pesquisa já a caracteriza quanto ao delineamento, como estudo de campo, que corresponde à coleta direta de informação no local em que acontecem os fenômenos. Quanto à natureza, a pesquisa caracteriza-se como de abordagem qualitativa, sendo o estudo de nível exploratório e descritivo, uma vez que se desenvolve com o objetivo de proporcionar uma visão geral, de tipo aproximativa, com observação e entrevista sobre determinado fato, que corresponde à existência ou não de práticas de aprendizagem na biblioteca universitária. Objetivou-se também, uma vez existindo, 
descrever as categorias que identificassem as práticas de organizações do conhecimento nas Bibliotecas em estudo, conforme a variável aprendizagem do Modelo de Organização do Conhecimento apresentado por Angeloni (2002) e adotado como parâmetro, o que caracteriza a pesquisa como descritiva.

Nesse prisma, adotamos o método do estudo de caso múltiplo, uma vez que "[...] É um meio de organizar dados sociais preservando o caráter unitário do objeto social estudado" (GOODE; HATT, 1969, p.422), analisando duas situações. Sua aplicação é adequada para responder às questões "como" e "por que", de cunho explicativo, tratando-se de relações operacionais que ocorrem ao longo do tempo, mais do que de freqüências ou incidências (BRESSAN, 2000, p.2).

Neste estudo, apresentamos os casos de duas bibliotecas universitárias, conforme veremos a seguir.

\subsection{Definições do universo e da amostra}

O universo de pesquisa equivale às bibliotecas universitárias localizadas no Estado da Paraíba. Considerando a impossibilidade de atingir esse universo e a distância geográfica entre elas, além do curto espaço de tempo para a realização da pesquisa, definimos como amostra as bibliotecas universitárias de grande porte localizadas em João Pessoa / $\mathrm{PB}$, correspondendo à da UFPB e à da UNIPÊ. Desse universo, selecionamos como colaboradores/informantes os bibliotecários, apontados pelos gestores das duas bibliotecas como pessoas-chave das organizações. Para isso, sugerimos que a direção considerasse a experiência e o envolvimento com as atividades da organização, porquanto essas pessoas geralmente são concebidas como detentoras do conhecimento tácito.

Para a caracterização da amostra, realizamos visitas aos campos de pesquisa. Primeiro, em reunião com a equipe da pesquisa e a direção das duas bibliotecas, explicamos o conteúdo do projeto e obtivemos a autorização para o seu desenvolvimento; em seguida requeremos a indicação dos nomes das pessoas-chave que pudessem representar as várias seções das bibliotecas, possibilitando a aplicação posterior dos instrumentos de pesquisa. Foram indicados 12 (doze) bibliotecários, comparecendo ao ambiente de coleta de dados oito profissionais, agrupados em duas equipes, sendo uma delas composta por três membros e a outra por cinco.

\subsection{Definição dos instrumentos de coleta e de análise dos dados}

Com dados preliminares cedidos pelas gestoras, elaboramos um planejamento para possibilitar a coleta dos dados, adotando-se a técnica de grupo focal instrumentalizada por entrevista e observação direta em equipe, paralelamente. Esses instrumentos foram aplicados durante um 
encontro de "Integração de Equipes", intitulado "Chá de compartilhamento de conhecimento", reunindo os bibliotecários da UFPB, do UNIPÊ e a equipe responsável pela pesquisa.

Para utilizar a técnica de grupo focal, portanto, consideramos seu planejamento, que contemplava o objetivo da pesquisa e suas metas; a definição do moderador e do observador; a elaboração da lista de questões para discussões; a escolha do local para a realização da reunião, atentando-se para a atmosfera; o recrutamento dos participantes e a seleção de dinâmicas (DIAS, 2000). Partindo desse planejamento, definimos as seguintes ações:

a) Objetivo: captar os significados e identificar categorias que caracterizem as Bibliotecas como organizações do conhecimento por meio da aprendizagem;

b) Meta específica: realizar um encontro denominado "Chá de Compartilhamento de Conhecimento", com duração de 3 horas e 30 minutos, em horário fora do expediente, possibilitando a participação de todos os membros;

c) Ambiente: Serviço Brasileiro de Apoio às Micro e Pequenas Empresas (SEBRAE) - João Pessoa/ PB, localizado em ponto central da cidade;

d) Atmosfera ou Praça: ambiente neutro, confortável, descontraído e climatizado. As acomodações para as equipes de colaboradores e pesquisadores foram distribuídas da seguinte forma:

equipe de colaboradores: cadeiras em círculo, formando dois grupos, permitindo a discussão e o seu registro;

equipe de pesquisadores: o moderador, acomodado no centro dos dois grupos, conduzindo a discussão; e os observadores, integrados um em cada equipe, anotando em blocos os eventos ocorridos;

mesa ornamentada com lanche, servido no intervalo da primeira sessão.

e) Moderador: coordenadora da pesquisa, com o papel de conduzir a discussão, facilitando o fluxo livre de idéias e a participação de todos;

f) Observadores: duas equipes (professoras, bolsista e voluntário), cada uma apoiando um grupo de colaborador, observando e recolhendo seus registros;

g) Animador: bibliotecária/administradora, responsável pela realização de dinâmicas de grupo: dinâmica de apresentação, de relaxamento, de descontração e de encerramento e avaliação.

Considerando esse planejamento e aplicando-se a técnica de grupo focal, a entrevista foi realizada de forma estruturada, tomando por base o processo de aprendizagem do modelo proposto por Angeloni (2002). Assim, o chá foi realizado seguindo o roteiro abaixo:

- entrega de material; 
- aplicação de dinâmica de grupo e integração dos colaboradores;

- apresentação do projeto de pesquisa e da equipe pesquisadora;

- apresentação da dimensão pessoas e sua variável aprendizagem;

- formulação da questão (moderador) correspondente ao item explanado;

- anotações (participantes) individuais sobre a questão da categoria em pauta, de acordo com a realidade vivenciada nas organizações;

- condução da discussão (coordenador) de modo que os participantes de cada equipe explanassem entre eles o que foi registrado e compartilhassem oralmente seu entendimento sobre a variável em questão;

- recolhimento dos blocos, feito pelo(s) observador(es) ( bolsista e voluntário);

- realização de dinâmicas de relaxamento, de descontração e de encerramento; e avaliação do encontro.

Durante o Chá, a observação, por sua vez, veio complementar as informações obtidas durante a discussão, reforçando o caráter qualitativo da pesquisa e registrando comportamentos e fatos não evidenciados por outras técnicas.

$\mathrm{Na}$ análise qualitativa, apresentamos citações diretas das frases que constam de indicadores que caracterizam as práticas de GC. Os dados coletados referentes à categoria aprendizagem e seus indicadores encontram-se analisados a seguir.

\section{Aprendizagem organizacional em bibliotecas universitárias: resultados de pesquisa}

Os resultados se referem à descrição analítica da categoria aprendizagem, e foram obtidos com o grupo focal, a entrevista e o registro da observação comportamental durante a realização do "Chá de Compartilhamento de Conhecimento".

\subsection{Sessão do grupo focal: descrição analítica da categoria aprendizagem}

Aprender significa compreender o passado, com a capacitação do presente, para a construção do futuro. Portanto, a aprendizagem é um processo de mudança resultante da prática ou experiência anterior. A aprendizagem individual apresenta uma cadeia que vai desde a reação ao ambiente na coleta de novos dados, passando pela significação, ocorrendo então a aprendizagem, que é aplicada pela tomada de decisão. A aprendizagem organizacional, que prescinde a grupal, por sua vez, toma 
Aprendizagem organizacional em unidades de informação: do grupo focal à comunidade de prática
Eneide Nóbrega Duarte; Alzira Karla Araújo da Silva; Edilene Toscano Galdino dos Santos; Isabel França de Lima; Marcos Paulo Farias Rodrigues; Suzana Queiroga da Costa

por base a aprendizagem individual; porém com a capacidade de criar novas idéias, aplicando e melhorando a organização do conhecimento da rotina em torno das atividades desenvolvidas e da cultura organizacional (ANGELONI, 2002). Partindo dessas afirmações, questionamos a equipe de bibliotecários das duas unidades estudadas:

Pergunta - Quais os estímulos apresentados pela Biblioteca em que você trabalha, em direção à sua aprendizagem individual e grupal? Cite quais as formas adotadas para promover sua aprendizagem e a dos demais.

\section{QUADRO 1 - Dimensão Pessoas - aprendizagem}

\begin{tabular}{|c|c|}
\hline \multicolumn{2}{|c|}{ DIMENSÃO PESSOAS - VARIÁVEL APRENDIZAGEM } \\
\hline $\begin{array}{l}\text { Unidades de Contexto } \\
\text { Equipe da Biblioteca1 }\end{array}$ & $\begin{array}{c}\text { Unidades de Contexto } \\
\text { Equipe da Biblioteca } 2 \\
\end{array}$ \\
\hline $\begin{array}{l}\text { "Há várias formas de incentivar a aprendizagem: } \\
\text { treinamento, participação em congressos, cursos, } \\
\text { oportunidade de realizar novas tarefas" (E1S1)*. }\end{array}$ & $\begin{array}{l}\text { "[...] já participei muito de treinamentos, cursos, } \\
\text { seminários, congressos etc" (E2S1). }\end{array}$ \\
\hline $\begin{array}{l}\text { “[...] treinamentos, participação em eventos } \\
\text { (seminários, congressos, cursos, participação em } \\
\text { especializaçôes oferecidas pela instituição (como } \\
\text { aluno bolsista))” (E1S2). }\end{array}$ & $\begin{array}{l}\text { "A minha instituição me deu bastante oportunidade } \\
\text { de me promover, como por exemplo: cursos, } \\
\text { treinamento, seminários. De forma que, através dos } \\
\text { mesmos, tive oportunidade de mostrar o meu } \\
\text { trabalho e demonstrar para o usuário tudo que } \\
\text { aprendi” (E2S2). }\end{array}$ \\
\hline \multirow[t]{3}{*}{$\begin{array}{l}\text { "Treinamento de pessoal partindo da direção da } \\
\text { biblioteca e direção geral, mini curso - iniciativa da } \\
\text { biblioteca - reuniões com debates direcionadas às } \\
\text { tarefas de cada funcionário, participação em } \\
\text { eventos, rodízio nos setores" (E1S3). }\end{array}$} & $\begin{array}{l}\text { "A aprendizagem foi através das participações em } \\
\text { congressos, seminários e reuniões técnicas e } \\
\text { treinamentos técnicos, e cursos. As formas adotadas } \\
\text { foram através da necessidade dos serviços que o } \\
\text { setor desenvolve” (E2S3). }\end{array}$ \\
\hline & $\begin{array}{l}\text { "As formas adotadas para o crescimento intelectual } \\
\text { das pessoas é feita através de participação em } \\
\text { congressos e seminários, como também treinamento } \\
\text { nas diversas áreas [...]" (E2S4). }\end{array}$ \\
\hline & $\begin{array}{l}\text { "Nenhum. Faz tempo que a Biblioteca não oferece } \\
\text { cursos para os bibliotecários" (E2S5). }\end{array}$ \\
\hline
\end{tabular}

Fonte: Dados da pesquisa.

* Adotamos os termos E1 e E2 para representar a Equipe 1 e Equipe 2, e os termos S1, S2 para representar o Sujeito 1 e Sujeito 2 .

A aprendizagem significa a necessidade de um contínuo aprendizado como forma de fazer frente às mudanças macro e micro-ambientais. Em sintonia com esse conceito, constatamos que, nos dois casos estudados, a aprendizagem apresenta-se como estímulo por intermédio de "treinamento" e "participação em eventos" (congressos, seminários), com maior incidência de respostas; seguido pela participação em "cursos" e a promoção de "reuniões"; e, com uma menor incidência, foi citada a oportunidade de realizar "novas tarefas", "mini curso", o "rodízio nos setores" e as "reuniões técnicas".

A premência apontada pelos bibliotecários da pesquisa no aprendizado contínuo destaca três pontos que merecem atenção: reuniões, rodízio nos setores e oportunidade de realizar novas tarefas. Percebemos nessas falas que, não apenas o incentivo e/ou patrocínio das 
Instituições em que atuam para a participação em processos de aprendizagem externos ao seu ambiente de trabalho, como cursos, especializações e treinamentos, são importantes, mas que também a ocorrência de eventos internos, em seu próprio ambiente, é também fator decisivo na aprendizagem.

Ao se reportarem às reuniões, os bibliotecários expressam que é no diálogo com seus pares e nas narrativas informais que 0 compartilhamento de aprendizado acontece. Da mesma forma, quando destacam o rodízio nos setores e as oportunidades de realizar novas tarefas, sinalizam o interesse numa aprendizagem sistêmica e a importância de se conhecer o todo da profissão e da unidade de informação que atuam.

Considerando a inserção das tecnologias de informação e comunicação na Biblioteconomia, bem como o avanço da área e das técnicas e práticas profissionais, o bibliotecário se vê no cerne da busca pelo conhecimento, para aplicar em sua prática, tornando a gestão da informação mais efetiva e eficiente. Para esse profissional da informação, que lida com o gerenciamento da informação em organizações, a habilidade de comunicação, a curiosidade e a adaptabilidade são necessárias para o trabalho técnico, administrativo e gerencial de informação. Por outro lado, a rotina e a passividade devem ser tidas como inimigas desse profissional (GUINCHAT; MENOU, 1994). Nesse sentido, além de uma formação básica sólida, cursos de aperfeiçoamento, como especialização, treinamentos e pós-graduação, consolidam as competências informacionais e proporcionam sua atualização permanente.

É oportuno ressaltar, ainda, as possibilidades de atuação do bibliotecário na Sociedade da Informação, que recai sobre diversas áreas. Valentim (2000) categoriza esse mercado em grupos: mercado informacional tradicional (bibliotecas públicas, universitárias, escolares, especializadas, centros culturais e arquivos); mercado informacional existente e não-ocupado (editoras, livrarias, empresas privadas, provedores de Internet, bancos e bases de dados); e mercado informacional de tendências (centros de informação/documentação de empresas privadas, bancos e bases de dados eletrônicos e digitais, portais de conteúdo e portais de acesso na rede global (Internet) e em redes institucionais internas (Intranet)). Essa ampliação no mercado ratifica a necessidade de aprendizado permanente e desenvolvimento de novas habilidades.

Consideramos, portanto, que a aprendizagem contínua repercute na atuação do bibliotecário, considerando-se que o mercado de trabalho:

[...] exige uma postura de criatividade, de renovação constante e de disposição para enfrentar desafios diários. 0 bibliotecário deve agregar aos conhecimentos adquiridos no curso de graduação vários ouros, que devem ser buscados em outros cursos e campos de conhecimento, à medida que os 
desafios e/ou dificuldades forem surgido (ARAÚJO; DIAS, 2005, p.121).

Nesse sentido, consideramos que o bibliotecário precisa estar atento diante das demandas do ambiente procurando a educação permanente.

Analisando os resultados sob o enfoque de Tacla e Figueiredo (2002), as Bibliotecas Universitárias estudadas estimulam e promovem a aprendizagem de seu pessoal, adotando a aquisição externa e interna de conhecimentos, conforme as falas de seus profissionais, literalmente registradas no QUADRO 1 e categorizadas no QUADRO 2.

QUADRO 2 - Categorização dos processos de aprendizagem da biblioteca do UNIPÊ e da UFPB

\section{CATEGORIZAÇÃO DOS PROCESSOS DE APRENDIZAGEM}

\begin{tabular}{l|l}
\hline \multicolumn{1}{c|}{ Aquisição externa de conhecimentos } & \multicolumn{1}{c}{ Aquisição interna de conhecimentos } \\
\hline \hline Treinamento externo & Treinamento interno \\
\hline Eventos (congressos, seminários) & Novas tarefas \\
\hline Curso (pós-graduação) & Rodízio nos setores \\
\hline Mini cursos & Reuniões técnicas \\
\hline
\end{tabular}

Fonte: Dados da pesquisa.

Essa categorização reflete os processos de aprendizagem comumente adotados nas bibliotecas universitárias estudadas, mostrando os estímulos apresentados para a aprendizagem individual e grupal. Ressalta-se a importância das vias identificadas por Garvin (2000) para promover a aprendizagem, que podem se enquadrar nas categorias do QUADRO 2. A resolução sistemática de problemas e a experimentação podem surgir na ocasião em que se atribui "novas tarefas" e "rodízio nos setores". Contudo, a experiência passada não aparece explicitamente, apesar de permear todo o processo de aprendizagem. A circulação de conhecimento, por sua vez, pode surgir no "treinamento interno e externo", nos "mini cursos" e nas "reuniões técnicas". Já as experiências realizadas por outras organizações não parecem ser contempladas pelas bibliotecas como processo de aprendizagem. O aprendizado em grupo, ressaltado por Senge (1990), é o nível que se destaca.

As motivações dos profissionais que buscam e interagem com os processos de aprendizagem individuais e grupais são diversas. Garvin (1998) ressalta que os profissionais que aprendem, atuando em empresas, sentem-se motivados pela competitividade (busca de manter a longevidade da empresa), pelo ambiente de mudanças permanentes (exigência de novas habilidades), entendimento de negócios (entender como as ações do presente influenciam no futuro), preparação para o 
futuro (construir um ambiente favorável ao seu gerenciamento), e pelo desempenho de equipes (organizar tarefas, acompanhar resultados e avaliar o sucesso). Essas motivações, pensamos, perpassam todo o profissional que se sente motivado a aprender, seja qual for o tipo de organização.

Ressaltamos que as Bibliotecas Universitárias em foco, ao passo que criam estruturas técnicas e profissionais que favorecem o intercâmbio de experiência entre seus membros ( $\mathrm{CHOO}, 2006)$, ganham características de organização do conhecimento. Nesse contexto, podemos aferir que "[...] o desenvolvimento da sociedade dependerá cada vez mais dos conhecimentos especializados e da aplicação deles na solução de problemas por pessoas especialmente treinadas [...]" (CUNHA, 2006, p.149).

A aprendizagem, integrada no ambiente organizacional, repercute no crescimento especializado dos seus profissionais e em seu desenvolvimento. Desse modo, o grupo tem o papel de integração, que liga a aprendizagem individual à organizacional (CYSNE, 2007).

\subsection{Resultados obtidos com a observação comportamental}

Paralelamente à técnica do grupo focal e à aplicação da entrevista, ocorreu a observação, cujos resultados demonstraram que as equipes estavam atentas, comprometidas com a pesquisa, pela atenção, interação e entendimento dos questionamentos, além da pontualidade na chegada ao local de realização do Encontro. Assim, destacamos o interesse no processo de aprendizagem, que, segundo Guitiérrez (2006, p.125) permite...

[...] de um lado, aumentar o conhecimento individual de um sujeito submetido ao processo, podendo resultar diretamente em uma melhora da contribuição desse mesmo sujeito na consecução dos objetivos da organização. Por outro lado, o aumento do conhecimento individual desse sujeito, pelo processo de conversão, aumentará também o conhecimento corporativo. Abre-se, assim, a possibilidade de que outros membros da organização possam beneficiar-se, aumentando seus conhecimentos individuais e, dessa forma, melhorar suas contribuições pessoais para a própria organização.

Esse interesse no processo de aprendizagem demonstrado pelos profissionais envolvidos na dinâmica do estudo, se bem aproveitado, poderá conduzir as Bibliotecas ao patamar das organizações que aprendem, contribuindo, assim, para o aumento da criatividade e da habilidade em identificar as oportunidades inovadoras. Na visão de Tomáel 
et al. (2007), a inovação depende da base de conhecimento da organização, sendo necessário, portanto, a facilitação da geração de novas idéias, bem como a troca de conhecimentos, experiências e informações, já que tudo isso fortalece e amplia os processos de aprendizagem.

A observação realizada durante a aplicação da entrevista com as duas equipes envolvidas conduz à seguinte interpretação: a concentração das equipes nas discussões dos temas evitou dispersão, favorecendo 0 entendimento dos questionamentos, possibilitando a interação entre as pessoas, contribuindo para a aprendizagem em Grupo Focal.

Essa experiência e os resultados confirmam que o GF colabora para a formação de comunidades de prática. Admitindo que "a metodologia de pesquisa apoiada na técnica dos grupos focais considera os produtos gerados pelas discussões grupais como dados capazes de formular teorias, testar hipóteses e aprofundar o conhecimento sobre um tema específico" (GONDIM, 2002, p.10), e considerando que o comportamento dos bibliotecários foi favorável à sua aplicação, percebemos nos resultados as limitações e possibilidades do processo de aprendizagem nas Bibliotecas focadas. Assim, os bibliotecários estão abertos ao aprendizado e as bibliotecas oferecem meios para tal. Contudo, vale destacar a necessidade de um plano de capacitação que defina metas e objetivos de acordo com o interesse e o perfil dos bibliotecários.

\section{Considerações finais}

A pretensão de mapear as práticas desenvolvidas pelas organizações estudadas para a promoção da aprendizagem organizacional, assim como a promoção mesma do processo de aprendizagem com as próprias experiências e as dos outros, adotando-se a técnica de grupo focal, mostraram resultados satisfatórios.

O estudo realizado com o grupo focal viabilizou identificar como as organizações estão trabalhando a questão da aprendizagem no seu ambiente, conduzindo os membros a discutir em equipe as idéias e a fazer um esforço de memória $e$, individualmente, registrando seus depoimentos. Isso fez com que a equipe pesquisadora percebesse os esforços e os limites para a promoção da aprendizagem organizacional. Os comentários feitos oralmente entre as equipes facilitaram a aprendizagem através da troca de experiências entre eles, embora estas fossem semelhantes. Apesar de serem organizações com naturezas distintas uma de caráter privado e a outra pública -, em nada diferiram quanto às práticas adotadas, certamente por serem afins quanto aos interesses profissionais.

Com base na literatura, para a apreensão de fenômenos mais complexos, como a aprendizagem de conceitos e a solução de problemas, foram empregados tanto dados objetivos quanto comportamentais. Assim, quanto aos aspectos comportamentais identificados por meio das 
observações, percebemos que as equipes interagiram, demonstrando interesse, seriedade e comprometimento com a prática profissional, e até vislumbrando a continuidade e a assiduidade de encontros como o "Chá de Compartilhamento de Conhecimento".

Considerando o compromisso, a integração e o interesse demonstrados pelos bibliotecários quanto ao processo de aprendizagem, sugerimos que seja desenvolvida em bibliotecas universitárias uma "qualificação integrativa da organização", na qual os bibliotecários de todos os setores da Biblioteca sejam envolvidos no desenvolvimento de projetos, integrando assim experiências, conhecimentos e expectativas.

Visto que as pessoas precisam trocar experiências com seus colegas, envidar esforços para reunir-se e partilhar histórias, para construir um conhecimento que as ajude a enfrentar as mudanças que surgem, faz-se premente, a partir da expectativa gerada no encontro de integração, a formação de uma comunidade de prática em unidades de informação, com a inserção das demais Bibliotecas Universitárias em funcionamento no Estado da Paraíba.

A partilha de experiências proporcionada pela técnica de grupo focal possibilitará a construção de um conhecimento coletivo de aprendizagem e de identidade, culminando com anseios de buscas coletivas de aprendizagem com outras comunidades, não necessariamente da mesma área, que possam agregar experiências inovadoras.

A formação de outros grupos focais pode gerar, na Biblioteca, uma série de inovações. Sugerimos que no processo de desenvolvimento de uma aprendizagem organizacional se estabeleçam projetos organizacionais integrativos, tais como a abertura de ilhas de aprendizagem; a qualificação e processos de melhoria contínua; treinamentos especializados e a integração entre grupos.

Em organizações formais, como as bibliotecas, o grupo focal auxilia na aprendizagem organizacional e também na geração de novas idéias, como a formação de comunidades de prática. A colaboração, nesse sentido, favoreceu esse grupo, e certamente favorecerá outros que vierem a ser formados e estudados em bibliotecas universitárias.

\section{Referências}

ARAÚJO, E. A.; DIAS, G. A. A atuação profissional do bibliotecário no contexto da Sociedade da Informação. In: OLIVEIRA, M. (Coord.). Ciência da Informação e Biblioteconomia: novos conteúdos e espaços de atuação. Belo Horizonte: UFMG, 2005. p.111-122.

ANGELONI, M. T. (Coord). Organizações do conhecimento: infraestrutura, pessoas e tecnologia. São Paulo: Saraiva, 2002. 215p.

BRESSAN, F. O método do estudo de caso. Administração On Line: Prática - Pesquisa - Ensino. FECAP, v. 1, n.1, jan./mar. 2000. Disponível em: <http://www.fecap.br/adm online/art11/flavio.htm> Acesso em: 13 dez. 2004. 
CHOO, C. W. A administração da aprendizagem: as organizações como empresas geradoras de conhecimento. In: A organização do conhecimento... 2.ed. São Paulo: Senac, 2006. p.179-252.

CUNHA, M. V. As profissões e as suas transformações na sociedade. In: CUNHA, M. V.; SOUZA, F. C. Comunicação, gestão e profissão: abordagens para o estudo da Ciência da Informação. Belo Horizonte: Autêntica, 2006. p.141-150.

CYSNE, F. P. Aprendizagem organizacional e serviços de informação: os componentes da transferência tecnológica. In: PINTO, V. B.; CAVALCANTE, L. E.; SILVA NETO, C. (Orgs.). Ciência da Informação: abordagens transdisciplinares, gêneses e aplicações. Fortaleza: Edições UFC, 2007. p.201-224.

DIAS, C. A. Grupo focal: técnica de coleta de dados em pesquisa qualitativa. Informação \& Sociedade: Estudos. João Pessoa, v.10, n.2, p.141-158, 2000.

DUGUID, P.; BROWN, J. S. Estrutura e espontaneidade: conhecimento e organização. In: FLEURY, M. T. L.; OLIVEIRA JÚNIOR, M. M. (Orgs.). Gestão Estratégica do conhecimento: integrando aprendizagem, conhecimento e competências. São Paulo: Atlas, 2001. p. 50-79.

FLEURY, A.; FLEURY, M. T. L. Estratégias empresariais e formação de competências: um quebra cabeça caleidoscópio da indústria brasileira. 2.ed. São Paulo: Atlas, 2001.

FLEURY, M. T. L.; OLIVEIRA JÚNIOR, M. M. Aprendizagem e gestão do conhecimento. In: CHIAVENATO, I. Gerenciando as pessoas: o novo papel dos recursos humanos nas organizações. Rio de Janeiro: Campus, 1999.

GARVIN, D. A. et al. Aprender a aprender. HSM Management, v.2, n.9, p.58-64, jul./ago. 1998.

GARVIN, D. A. Construindo a organização que aprende. In: GESTÃO do conhecimento. Rio de Janeiro: Campus, 2000. p. 50-81. (Coleção Harvard Business Review).

GOMES, M. E. S.; BARBOSA, E. F. A técnica de grupos focais para obtenção de dados qualitativos. Educativa: Instituto de Pesquisas e Inovações Educacionais. Fevereiro/1999. Disponível em: <http://www.educativa.org.br>. Acesso em: 19 nov. 2008.

GONDIM, S. M. G. Grupos focais como técnica de investigação qualitativa: desafios metodológicos. Paideia, São Paulo, 2002. Disponível em: <sites.ffclrp.usp.br/paideia/artigos/24/03.doc>. Acesso em: 10 maio 2008.

GOODE, W. J.; HATT, P. K. Métodos em pesquisa social. 3.ed. São Paulo: Cia Editora Nacional, 1969.

GUINCHAT, C.; MENOU, M. Introdução geral às ciências e técnicas da informação e documentação. Brasília: IBICT, 1994. 
GUTIÉRREZ, Mario Pérez-Montoro. O conhecimento e sua gestão em organizações. In: TARAPANOFF, K. (Org.). Inteligência, informação e conhecimento. Brasília: IBICT, UNESCO, 2006. p.117-155.

DUGUID, P.; BROWN, J. S. Estrutura e espontaneidade: conhecimento e organização. In: FLEURY, M. T. L.; OLIVEIRA JúNIOR, M. M. (Orgs.). Gestão Estratégica do conhecimento: integrando aprendizagem, conhecimento e competências. São Paulo: Atlas, 2001. p. 50-79.

MEIRELLES, D. C. A inovação através do aprendizado coletivo em um contexto pós-moderno. In: STAREC, C.; GOMES, E. B. P.; CHAVES, J. B. L. (Orgs.). Gestão estratégica da informação e inteligência competitiva. São Paulo: Saraiva, 2005. Cap.18, p.271-282.

MENGALLI, N. M. Conceitualização de comunidade de prática - CoP. Disponível em: <http://www.projeto.org.br/emapbook/map neli.htm>. Acesso em: 19 fev. 2008.

RESSEL, L. B.; GUALDA, D. M. R.; GONZÁLES, R. M. B. Grupo focal como estratégia para coletar dados de pesquisa em enfermagem. International Journal of Qualitative Methods, v.1, n. 2, 2002 citado por DIAS, C. A. Grupo focal: técnica de coleta de dados em pesquisa qualitativa. Informação \& Sociedade: Estudos. João Pessoa, v.10, n.2, p.141-158, 2000.

SENGE, P. A quinta disciplina: arte, teoria e prática da organização de aprendizagem. 11.ed. São Paulo: Best Seller, 1990.

TACLA, C. L.; FIGUEIREDO, P. N. Acumulação de competências tecnológicas e os processos subjacentes de aprendizagem na indústria de bens de capital: o caso da Kvaerner Pulping do Brasil. In: ENCONTRO DA ASSOCIAÇÃO NACIONAL DE PÓS-GRADUAÇÃO E PESQUISA EM ADMINISTRAÇÃO - ENANPAD, 26., 2002, Salvador. Anais... Rio de Janeiro: ANPAD, 2002. 1 CD-ROM.

TOMÁEL, M. I. et al. A contribuição do processo de inteligência competitiva para a inovação nas organizações. In: VALENTIM, M. L. P. (Org.). Informação, conhecimento e inteligência organizacional. 2.ed. Marília: FUNDEPE, 2007. cap. 9, p.155-175.

VALENTIM, M. L. Atuação e perspectivas profissionais para o profissional da informação. In: (Org.). Profissionais da informação: formação, perfil e atuação profissional. São Paulo: Polis, 2000. p.135-152.

VEIGA, L.; GONDIM, S.M.G. A utilização de métodos qualitativos na ciência política e no marketing político. Opinião Pública. v.2, n.1, p. 1-15, 2001. 